\title{
Teachers' perceptions of humour as a classroom teaching, interaction, and management tool
}

\author{
Michael Lovorn \\ University of Pittsburghw \\ mlovorn@pitt.edu
}

Calli Holaway

Tennessee State University

cholaway@tnstate.edu

\begin{abstract}
Although research into humour in education contexts has increased sharply over the past decade, there are still relatively few studies related to its impact on specific elements of classroom dynamics such as teaching, student/teacher interaction, and classroom management. Teachers' perceptions of the use of humour as a teaching, interaction, and management tool likely shape the educational experiences for all stakeholders. This study used online discussions to explore perceptions among kindergarten through grade $12(K-12)$ teachers of the use of humour as a teaching, interaction, and management strategy in the classroom. These discourses revealed participating teachers $(n=31)$ have some understanding of how humour impacts teaching and learning, students' engagement and motivation, teachers' confidence and interaction with students, and various challenges and resistances to the use of humour in the classroom. Findings indicated that while most participating teachers could demonstrate examples of their use of humour in the classroom, few appeared to perceive humour as a structured classroom strategy. Additionally, the study revealed that while participating teachers are open to the idea of using humour in the classroom, most do not deliberately or strategically include it in the planning or implementation of their lessons. Participants' responses consistently showed that humour "just happened" in the classroom and that it was part of a teacher's responsibility to ensure that humour did not distract from learning activities. Participating teachers identified many more negative than positive factors that influenced their decisions about using humour in the classroom.
\end{abstract}

Keywords: humour, teaching strategies, classroom management. 


\section{Introduction}

Researchers recognise the depth, breadth, and subjectivity in defining humour, and the challenges in measuring its scope and appropriateness in public settings. These and related ambiguities have often hamstrung humour research, particularly in education settings, for three central reasons: (1) it has proven difficult to carry out focused investigations of a topic considered to be so subjective; (2) due to this subjectivity, humour as a strategy has historically garnered limited academic respect from education scholars; and (3) as articulated by Mary Kay Morrison (2008: 73), there exists a "humour paradox" in education settings, wherein we speak openly about our appreciation of sense of humour, but demonstrate some reluctance to, and even uncomfortability in, participating in humour exchanges in the classroom. The purpose of this study was to explore pre-service teachers' perceptions of how, when, and why they use humour in the classroom, and to discuss perceived barriers to doing so.

Humour may be broadly defined as the quality of being amusing or comic; the ability to make other people laugh. In the context of this study, humour, more specifically, incorporates the focused and structured amusing or comic words, actions, or reactions of a teacher in the act of teaching, engaging and interacting with students, managing a classroom, and/or setting a tone for timely and appropriate mirthful response to content or activities (Latta 1999; Berk 2002). Examples of a teacher's structured use of humour relating to content might include allowing students to identify irony or hyperbole in a historical account or primary document, or to demonstrate comprehension of literary concepts by re-explaining them to classmates through a humorous lens or explanation. An example of a teacher's structured use of humour to engage or interact with students might be to present herself as more approachable by making light-hearted, self-effacing comments. Finally, an example of a teacher's use of humour in classroom management might be to present students with absurd hypothetical situations or consequences to class rules violations. For purposes of this study, this conceptualisation does not include impromptu uses of humour, sarcasm, or banter between the teacher and students or students and their peers.

Studies indicate teachers' use of humour as a teaching, interaction, and/or management tool may lead to improvements in students' attention, motivation, and learning (Chapman \& Foot 1976: 94; Forsyth et al. 1997: 2-3; Berk 2002: 10; Gurtler 2002: 5). Humour can also help make the classroom a more comfortable and engaging learning environment for students, encouraging their academic and behavioural success (Lovorn 2009: 15; Posnick-Goodwin 2009: 17; Beard \& Wilson 2013: 216). Furthermore, age appropriate, structured humour teaching and interaction strategies have been shown to lead to higher order thinking, increased creativity, and deep knowledge relating to subject matter among students (Henry 2000: 64; Paterson 2006: 43-44; Lovorn 2008: 2). Some teachers also perceive challenges to the use of humour in the classroom, including fear of losing control of students (Grow 1995: 1; Steele 1998: 3); and resistance to the use of humour in the classroom, including pressure from school administrators to avoid it at all costs (Lovorn 2009: 20). Additionally, researchers identify societal complexities and paradoxes that contribute to a general hesitancy among teachers to engage in humour in educational settings (Berk 2002: 9; Gurtler 2002: 16; Morrison 2008: 73). The purpose of this study is to explore perspectives and deeper strands of thought among kindergarten through grade 12 (K-12) teachers' about the effectiveness of using humour in the classroom, particularly as it relates to classroom teaching, classroom management, and teacher/student and student/student interaction. 
Research indicates humour can be an effective teaching and classroom management tool, fostering engagement, academic development, and confidence-building among students of all ages (Harlin 2008: 125). According to Hickman \& Crossland (2004-2005: 226) and Mawhinney (2008: 207-208), humour can enrich and broaden learning by establishing a predictably welcoming environment wherein students are enabled to interact and grow socially and academically. Cornett (2001: 34), Morrison (2008: 2, 24), and Walker (2008: 66) each observed that teachers who model and employ appropriate humour strategies embolden their students to perceive learning, content, and behaviour in relevant, engaging, and dynamic manners, and promote students' positive attitudes toward school, coursework and each other. Additional research indicates that humour enriches the learning environment and students' learning opportunities by increasing their motivation (Levine 2006), providing a relaxed and comfortable environment in which to learn (Shiyab 2008: 623), and even increases students' cognitive brain functioning (Klein 1995).

These findings have far reaching implications on teaching and learning, and the learning environment. Students who are socially, physically, and emotionally comfortable are more motivated to learn and more receptive to the teacher, her instruction, and expectations (Frymier \& Wanzer 1998; James 2001: 6; Beavers 2011: 418-419). Research in the field of psychology has suggested that humour may serve as a coping, defence strategies, psychological distress, and well-being mechanism for many adolescents (Erickson \& Feldstein 2007), and that there are even measurable positive impacts of humour on one's physical health (Payne et al. 2008). In a classroom setting, laughter, when utilised appropriately, enables this increased level of comfortability, and makes for a more welcoming yet intellectually demanding learning environment (Latta 1999; Frymier et al. 2008; Lovorn 2009: 21). Additionally, teachers have described the values and successes of using discipline-specific or topical humour in their efforts to engage learners (Farber 2007: 67; Tuncay 2007: 10; Copp \& Kleinman 2008: 121-122).

Although research has shown that humour can be an effective classroom strategy, both in terms of classroom environment and in student learning, few studies have focused on how teachers actually incorporate humour into the classroom. This study begins to fill the gap in the literature by exploring how and when teachers choose to utilise humour in the classroom, as well as what factors influence teachers' decisions on using humour.

\section{Methodology}

This study used a content analysis methodology to analyse data acquired from an online dialogue between 31 teachers teaching in suburban and urban schools in a city of about 100,000 in the Southern U.S. According to Neuendorf (2002), content analysis is particularly appropriate for narrative data that are largely contextual and have been collected in an electronic format. All participants were in-service teachers enrolled in a master's level education course at a major university. As part of the course, participants were required to respond to online discussion prompts and were encouraged to respond to postings from other students in the course. Participants were not asked to respond to the prompts in any particular order and were free to express whatever opinion they desired with no negative repercussions on their course grade. Data for this study were collected over a period of 15 weeks.

Data were analysed to answer the following research questions:

1. What are teachers' perceptions of the use of humour as a teaching strategy?

2. What influences have led to teachers' various uses of humour as a teaching strategy? 
3. How, when, and why teachers use humour in the classroom?

4. Do teachers feel they have a responsibility to help students develop a sense of humour or enable their learning though humour?

5. What, if any, barriers, resistances, or other challenges do teachers encounter or observe regarding the use of humour strategies in the classroom?

\section{Discussion prompt development}

It is the belief of the researchers that teachers' experiences with humour in the classroom, both in their roles as teachers and as students, influence whether they choose to use humour in their own classrooms. Additionally, teachers' experiences with humour influence the type and frequency of humour that they choose to utilise. A thorough review of the literature revealed that no instruments exist that measure teachers' perceptions of using humour in the classroom. Therefore, open-ended questions were developed by the researchers in order to obtain information about teachers' perceptions and experiences with humour in the classroom.

Due to the limited amount of research on the use of humour in the classroom, it was difficult to form a theoretical framework from which to develop questions. In order to develop a theoretical framework, the researchers created several questions based on their own experiences as classroom teachers with using humour. These items were used to conduct informal interviews with 20 in-service teachers in order to identify patterns of responses. Data from the informal interviews revealed some common themes regarding teachers' perceptions of using humour in their classrooms:

- Humour as a classroom strategy

- Humour as a part of teacher preparation

- Factors that influence teachers' decisions to use or not use humour in the classroom

- The influence of humour on student learning

- Restricted use of humour in the classroom due to the perceptions of others, particularly administrators

From the identified themes, open-ended discussion prompts were created. Eight prompts were originally developed; however, preliminary analysis of the first several responses revealed a low response rate and overlapping answers for some questions. Based on these preliminary results, three questions were eliminated for the remainder of the data collection period. Responses for the removed items were not included in the data analysis, as participants in their responses to the remaining questions reiterated all information contained in the responses to those three items. The final discussion prompts utilised for this study are listed in Appendix A.

\section{Data analysis}

The initial coding scheme was developed from the discussion prompts and consisted of the following themes:

- Classroom Effectiveness (CE)

- Teacher Preparation (TP)

- Positive Factors that influence teachers' decisions to use humour in the classroom (PF)

- Negative Factors that influence teachers' decisions to use humour in the classroom (NF) 
- Student-Student Interaction (SS)

- Teacher-Student Interaction (TS)

To evaluate the fit of the initial coding scheme to the data, two independent researchers coded approximately 10 per cent of the participant responses. Subsequent discussion of the coding process revealed that the initial coding scheme was not adequate. Specifically, it was difficult for the researchers to come to a practical conceptualisation of how to separate out SS and TS. In addition, the initial coding process revealed that different aspects of classroom effectiveness needed to be separated out. Therefore, changes were made to the coding scheme based on the initial examination of the data and the following themes were utilised in the final analysis. Descriptions of each of the themes can be found in Appendix B.

- Classroom Effectiveness: Management (CEM)

- Classroom Effectiveness: Teaching (CET)

- Classroom Effectiveness: Interaction (CEI)

- Teacher Preparation (TP)

- Positive Factors that influence teachers' decisions to use humour in the classroom (PF)

- Negative Factors that influence teachers' decisions to use humour in the classroom (NF) In order to establish inter-rater reliability, two independent researchers utilized the final coding scheme to code approximately 10 per cent of the participants' responses. Analysis revealed that the two researchers agreed on 92 per cent of the coded responses. The researchers discussed and reached a consensus for any discrepancies in the coding. A single researcher then coded the remaining 90 per cent of the participants' responses.

The coded data were compiled by theme and examined for consistency in responses. If at least two participants provided a similar response, it was noted as a sub-theme and reported in the results. Several participants gave specific examples of how they personally use humour in the classroom. Examples were noted and included in the results as deemed appropriate by the researchers

\section{Results}

\subsection{Classroom effectiveness: Management}

Overall, participants in the study agreed that humour could be an effective classroom management tool when used properly. In particular, participants indicated that humour was often used to capture students' attention or encourage students to be in class. They believed this use of humour was more efficient and more effective than many common classroom management approaches, particularly those with apathetic or negative feedback or connotations.

All participants agreed that using humour in the classroom helped create a positive classroom environment, which reduced the stress of the students and encouraged students to be more open to discussion. As one participant stated, "creating a positive environment for learning means being able to have students feel happy, comfortable, and open in the learning environment...their knowledge that it is OK to laugh and find the light side of issues helps this happen". Most participants indicated that they use humour on a regular basis in the classroom to help establish a warm, caring environment where students were comfortable with learning.

However, participants also indicated that the use of humour needs to be carefully monitored, as students frequently have not developed the social skills to understand when humour is not 
appropriate. In particular, participants stated that teachers must have the ability to "rein students in" when it was time to "get serious and focused". Humour was to be utilised in a limited manner as deemed appropriate by the teacher.

\subsection{Classroom effectiveness: Teaching}

Participants' responses regarding the impact of humour on teaching were overwhelmingly positive. Participants expressed the belief that using appropriate humour in the classroom increased student engagement and motivation. In addition, the use of humour facilitated students' willingness to take risks in the classroom, ensuring that students more willingly shared thoughts, participated in discussion, and engaged in exploratory or inquiry-based lessons.

Participants also believed that using humour in the classroom improved student learning of content. Several participants gave specific examples of how the use of humour helped connect students with the content being covered. In addition, humour provides another strategy for teachers to use to increase content retention and improve higher order thinking skills.

In this theme, several participants expressed concern over their responsibilities as teachers in using humour with their students. Participants disagreed on whether it was teachers' responsibility to develop their students' senses of humour. However, most participants acknowledged that the humour that a teacher uses could impact what students perceive as appropriate. Participants indicated that teachers should model appropriate humour, particularly with sensitive subjects such as race, gender, and socioeconomic status. Teachers should carefully consider any humorous resources that are to be utilised in the classroom. One participant specifically noted that some forms of humour (i.e., political cartoons) "can sometimes have dangerous intentions" and must be used with care. Students must learn that humour can often contain underlying messages and teachers should focus on how to teach students when humour is appropriate to use and when it is not.

While participants stated that it is important for teachers to model appropriate humour, several also indicated that humour is frequently not used in the classroom because teachers do not plan to use humour. Participants indicated that they needed to become more aware of potentially humorous situations in their classroom so that they can take advantage of these situations and improve student learning. In addition, participants stated that teachers should make the conscious decision to include humour in the classroom and allow time for students to express themselves through humour. The participants believed that presenting learning as fun would ensure that students become life-long learners.

\subsection{Classroom effectiveness: Interaction}

Participants expressed that humour in the classroom can both positively and negatively impact classroom interactions. Several participants stated that using humour helped them get to know their students better and reduced student anxiety. Additionally, humour helped students to be more comfortable with both the teacher and other students. As one participant stated, "humour is one of the greatest tools for levelling the social playing field, to help everyone feel that they belong". Participants also stated that humour can help students from different cultural backgrounds connect, developing students' patience, respect, and openness.

Interestingly, participants also stated that humour could contribute to students' selfconfidence. Participants agreed that when a teacher uses appropriate humour, students are more comfortable and therefore more willing to participate in class, thus leading to increased 
confidence. A few participants stated that they allow students to tell jokes and relate funny anecdotes to increase students' confidence in speaking in front of other people.

While most participants agreed that humour in the classroom could be a positive influence, they also stated that humour must be used cautiously. Participants believed that teachers were responsible for ensuring that humour among students was not destructive or hurtful. One participant stated that the teachers could model the appropriate use of humour, thereby helping students develop their own sense of "measuring and controlling the limits of humour, [to] know when humour is appropriate and when to stop".

\subsection{Teacher preparation}

Participants overwhelmingly indicated that they had not received any formal training on using humour in the classroom, either as part of their pre-service education programmes or as inservice teacher professional development. However, participants stated that they had gained knowledge of how to use humour in the classroom from observing other teachers, particularly teachers that they had when they were students. Participants indicated that when they were in classes where the teachers used humour, they were more comfortable and motivated, and that they hoped to emulate those teachers in their own classrooms. However, some participants stated that, because they had not received training on how to use humour appropriately, they were hesitant to incorporate humour in the classroom.

\subsection{Positive factors that influence teachers' decisions to use humour in the classroom}

Participants consistently cited aspects of classroom climate when identifying factors that influenced their use of humour in the classroom. Specifically, participants believed that laughter in the classroom helped students learn more easily and retain information more effectively. Using appropriate humour helped students feel good about them and about learning, and could be used with any content that was being taught.

Some participants cited specific examples of using humour as a tool for more effective teaching. One participant stated that using humour at the beginning of each class period provided an incentive for students to come to class on time, which was more effective than the negative incentive that was used when students were tardy. Other participants stated that they had been able to use humour to develop good citizens and to help students learn to make good choices. The use of humour allowed for students to be more comfortable with reflecting and sharing their thoughts, and provided teachers with the opportunity to teach students how to be respectful of others.

\subsection{Negative factors that influence teachers' decisions to use humour in the classroom}

Participants cited several negative influences when considering using humour in the classroom. The primary concern of the participants with using humour in the classroom was being able to maintain classroom control. Nearly every participant expressed the idea that humour could be disruptive and make classroom management difficult. However, participants also indicated that teachers could use these situations as teachable moments and show students how to determine when it is appropriate to be funny.

Participants also indicated that it can be difficult for teachers to keep the focus on classroom content if too much humour is used, and the use of humour may encourage students to 
"oversimplify or dilute important concepts or themes". Some participants also indicated that a teacher could unwittingly demonstrate prejudice through humour that could be detrimental to the classroom environment and student learning. Concerns were also expressed that some teachers that may have not developed a sense of which humour is appropriate for a particular grade level. Since students can learn much about what is funny and what is not by watching their teachers, it is vital that teachers consider carefully the humour they use in the classroom, particularly with sensitive subjects such as race, religion, politics, and sexuality. In addition, teachers need to be aware of how different types of humour can be interpreted by different cultures. Participants stated that teachers should not use humour when a student gives a wrong answer, nor should teachers allow students to make fun of each other. If teachers do not consider how students will interpret humour, they may embarrass or hurt a student, thereby reducing their effectiveness as a teacher.

The personality of the teacher should also be considered when choosing to use humour in the classroom. Participants indicated that teachers with more serious dispositions may not be able to use humour effectively, and that attempts to use humour could be perceived by students as "fake or ridiculous". Teachers who were not comfortable using humour in the classroom should not be forced to do so, nor should the use of humour in the classroom be formally assessed. Participants also stated that finding humorous materials or planning to use humour could take extra time and energy to incorporate.

\section{Discussion}

Results of this study revealed that, while teachers are open to the idea of using humour in the classroom, most do not deliberately include humour in the planning or implementation of their lessons. Teachers' responses consistently showed that humour "just happened" in the classroom and that it was part of a teacher's responsibility to ensure that humour did not distract from the content of the lesson or be hurtful to other students. In addition, teachers identified many more negative than positive factors that influenced their decisions about using humour in the classroom.

Interestingly, most teachers in this study indicated that they used humour to establish a positive classroom atmosphere, to motivate students, and to help students feel more comfortable, while at the same time, teachers expressed that humour could be a distraction in classroom and detrimental to learning. It is apparent that humour must be used appropriately, although teachers in this study indicated concerns about how teachers might impose their own senses of humour on students. Teachers in this study were divided on whether they were responsible for helping students develop senses of humour, but were clear on that the importance of teachers guiding students in determining when humour was appropriate. Several teachers referred to modelling appropriate humour for their students, and expressed the importance of teachers helping their students define the limits of humour. This demonstrates that teachers believed that humour is part of the social aspect of teaching, not necessarily a structured classroom strategy. Additionally, teachers also stated that not all teachers have developed an appropriate sense of humour themselves; therefore, encouraging all teachers to use humour in the classroom could actually be detrimental to students and the social structure of the classroom.

Teachers in this study demonstrated a limited perspective on what they defined as "humour". Teachers consistently referred to events in the classroom as being "funny" or "silly". Therefore, teachers were viewing humour simply as something that makes people laugh. This 
narrow view of humour ignores other types of humour, such as caricature, irony, or satire that may be useful in the classroom as learning strategies. In fact, teachers indicated that humour related to issues of religion, political affiliation, race, or sexuality should be avoided in the classroom; however, exposing students to editorials or political cartoons related to these subjects may be an impetus for valuable conversations that ultimately lead to increased understanding and tolerance. These findings may be directly related to the teachers' revelation that they had virtually no formal training on how to use humour in the classroom. Additionally, this broader definition of humour introduces types of humour that must be intentionally included in the classroom. Since teachers stated that they planned to utilise humour in their lessons, it is not surprising that their definition of humour was limited to types of humour that provoke laughter.

The analysis of teacher responses revealed an interesting dichotomy: teachers believed that the use of humour was more effective at managing student behaviour than many common classroom management approaches, including those with apathetic or negative connotations, but, at the same time, teachers feared that using humour could actually undermine a teacher's ability to control the classroom. Teachers in this study appeared to struggle with the idea of consciously using humour as a classroom management strategy. Results indicated that teachers believed that humour should be used more frequently in the classroom, the belief that making learning fun for students assists in the development of life-long learners was prevalent. However, teachers in this study expressed reluctance to incorporate humour out of the fear that something "inappropriate" might happen in the classroom. This may be a result of the lack of formal training on using humour, or it may be based in deeper beliefs about how the classroom climate should be structured. It is logical to assume that teachers who primarily focus on having a quiet, controlled classroom would express more resistance to including humour in the classroom.

In comparing these findings with those of existing research, researchers confirmed the perception of a "humour paradox" (Morrison 2008: 73), as well as evidence that teachers' use of humour as a teaching, interaction, and/or management tool may lead to improvements in students' attention, motivation, and learning (Chapman \& Foot 1976: 94; Forsyth et al. 1997: 23; Berk 2002: 10; Gurtler 2002: 5). While these findings are not generalisable, this paper advanced the knowledge base by further informing humour researchers about teachers' perceptions regarding the likelihood that age appropriate, structured humour teaching and interaction strategies have been shown to lead to higher order thinking, increased creativity, and deep knowledge relating to subject matter among students (Henry 2000: 64; Paterson 2006: 4344; Lovorn 2008: 2).

The results of this study demonstrate that teachers are willing to use humour in the classroom, but also view humour as a potentially dangerous tool. These and related findings also provide a basis for further study into the use of humour in the classroom, while also presenting suggestions for teacher practice. Teachers should be encouraged to pursue formal training on the use of humour in the classroom. Learning about how to use humour effectively exposes teachers to new methods of teaching and managing students. By broadening the definition of humour, additional resources and strategies are made available to teachers, so that students can more effectively learn content as well as social skills.

\section{Appendix A}

Discussion Prompts

1. What are your perceptions of the use of humour as a teaching strategy? 
2. What influences have led you to explore humour as a teaching strategy?

3. Briefly describe how, when and why you use humour in your classroom.

4. Do you feel you have a responsibility to help students develop sense of humour or enable they're learning though humour? Why or why not?

5. Describe any barriers, resistances, or other challenges you have encountered or observed regarding the use of humour strategies in the classroom. To what do you attribute these challenges?

\section{Appendix B}

Final Coding Scheme

Classroom Effectiveness: Management (CEM)

Includes how teachers use humour to maintain or establish classroom control. Also includes both positive and negative impact of humour on the classroom climate or on classroom management effectiveness.

\section{Classroom Effectiveness: Teaching (CET)}

Includes how teachers use humour to capture or maintain student attention, involvement, and participation. Also includes the impact of humour on student motivation. Includes intentional selection of the use of humour on the part of the teacher when designing or implementing lesson plans as well as teacher perceptions of how humour impacts students' learning of content, both in a positive and negative sense.

\section{Classroom Effectiveness: Interaction (CEI)}

Includes how humour can impact students' social interactions with other students and how humour can influence students' social development. Also includes how humour can impact students' social interactions with the teacher and perceptions of the teacher on how using humour can help meet the emotional and social needs of students. Includes both positive and negative impact of humour on teacher to student interaction and student to student interaction. Does not include the use of humour as a method for increasing student motivation or attention or as a classroom management method.

\section{Teacher Preparation (TP)}

Includes both formal and informal training that teachers have received on using humour in the classroom. Training may have come from teacher preparation programs, professional development opportunities, observations of other teachers, and/or reading practitioner or researchbased articles on classroom humour. Also includes teachers' lack of preparation on how to use humour in the classroom.

Positive Factors that influence teachers' decisions to use humour in the classroom (PF) Includes perceptions of the use of humour as appropriate to classroom instruction. Also includes perceptions of how using humour in the classroom may meet with approval from other teachers, administrators, parents, and students. Includes personal experience as teachers with positive impacts of using humour in the classroom, but does not include observations of other teachers using humour. 
Negative Factors that influence teachers' decisions to use humour in the classroom (NF) Includes perceptions of the use of humour as inappropriate to classroom instruction. Also includes perceptions of how using humour in the classroom may meet with disapproval from other teachers, administrators, parents, and students. Includes personal experience as a teacher with barriers, resistance, and challenges to using humour in the classroom, but does not include observations of other teachers using humour.

\section{References}

Beard, C. \& Wilson, J. P. (2013). The Power of Experiential Learning: A Handbook for Education, Training and Coaching ( $3^{\text {rd }}$ ed.). London: Kogan Page.

Beavers, S. L. (2011). 'Getting political science in on the joke: Using 'The Daily Show' and other comedy to teach politics'. Political Science and Politics 44 (2), pp. 415-419.

Berk, R. A. (2002). Humour as an Instructional Defibrillator: Evidence-based Techniques in Teaching and Assessment. Sterling, VA: Stylus Publishing.

Chapman, A. J. \& Foot, H. C. (eds.). (1976). Humour and Laughter: Theory, Research and Applications. London: John Wiley \& Sons.

Copp, M. \& Kleinman, S. (2008). 'Practicing what we teach: Feminism strategies for teaching about sexism'. Feminist Teacher: A Journal of the Practices, Theories, and Scholarship of Feminist Teaching 18 (2), pp. 101-124.

Cornett, C. E. (2001). 'Learning through laughter... again'. Bloomington, IN: Phi Delta Kappa Educational Foundation, pp. 1-45.

Erickson, S. J. \& Feldstein, S. W. (2007). 'Adolescent humour and its relationship to coping, defence strategies, psychological distress, and well-being'. Child Psychiatry and Human Development 37 (3), pp. 255-271.

Farber, J. (2007). 'Toward a theoretical framework for the study of humour in literature and other arts'. Journal of Aesthetic Education 41 (4), pp. 67-86.

Forsyth, G. A., Altermatt, E. R. \& Forsyth, P.D. (1997). 'Humour, emotional empathy, creative and cognitive dissonance'. Paper presented at the $105^{\text {th }}$ Annual Meeting of the American Psychological Association. Chicago, IL, 18-20 August.

Frymier, A. B. \& Wanzer, M. B. (1998). 'Make 'em laugh and they will learn: A closer look at the relationship between perceptions of instructors' humour orientation and student learning'. Paper presented at the $84^{\text {th }}$ Annual Meeting of the National Communication Association. New York, 23 November.

Frymier, A. B., Wanzer, M. B. \& Wojtaszczyk, A. M. (2008). 'Assessing students' perceptions of inappropriate and appropriate teacher humour'. Communication Education 57 (2), pp. 266288.

Grow, G. (1995). 'Using Humour to Help Students Respond to One Another's Writing'. Available online: http://www.longleaf.net/ggrow/humor.html [Accessed on 28 October 2015].

Gurtler, L. (2002). 'Humour in educational contexts'. Paper presented at the 110th Annual Meeting of the American Psychological Association. Chicago, 23 August.

Harlin, R. P. (2008). 'What do you really know about learning and development?' Journal of Research in Childhood Education 23 (1), pp. 125-134.

Henry, M. (2000). 'History and humour: A natural partnership'. OAH Magazine of History 14 (2), pp. 64-65. 
Hickman, G. P. \& Crossland, G. L. (2004-2005). 'The predictive nature of humour, authoritative parenting style, and academic achievement on indices of initial adjustment and commitment to college among college freshmen'. Journal of College Student Retention Research Theory and Practice 6 (2), pp. 225-245.

James, D. L. (2001). Split a Gut and Learn: Theory and Research. Farmington Hills, MI: Oakland Community College, pp. 1-12.

Klein, A. J. (1985). 'Children's humour: A cognitive-developmental perspective'. Education Resources Information Centre Online submission (ED265937), pp. 1-45.

Latta, R. L. (1999). The Basic Humour Process: A Cognitive-shift Theory and the Case Against Incongruity. Berlin: Mouton de Gruyter.

Levine, J. (ed.). (2006). Motivation in Humour. Edison, NJ: Aldine Transaction.

Lovorn, M. (2008). 'Humour in the home and in the classroom: The benefits of laughing while we learn'. The Journal of Education and Human Development 2 (1), pp. 1-12.

Lovorn, M. (2009). 'Three easy ways to bring humour into the social studies classroom'. The Leader 23 (1), pp. 15-16, 20-21.

Mawhinney, L. (2008). 'Laugh so you don't cry: Teachers combating isolation in schools through humour and social support'. Ethnography and Education 3 (2), pp. 195-209.

Morrison, M. K. (2008). Using Humour to Maximize Learning: The Links between Positive Emotions and Education. Lanham, MD: Rowman \& Littlefield.

Neuendorf, K. A. (2002). The Content Analysis Guidebook. Thousand Oaks, CA: Sage Publications.

Paterson, J. (2006). 'Did you hear the one about...? Humour in the classroom'. Middle Ground 10 (2), pp. 43-45.

Payne Bennett, M. \& Lengacher, C. (2008). 'Humour and laughter may influence health: III. Laughter and health outcomes'. eCAM 5 (1), pp. 37-40.

Posnick-Goodwin, S. (2009). 'Laughter makes you smarter'. California Educator 13 (4), pp. 1620.

Shiyab, S. M. (2008). 'Humour as a teaching strategy', in Mantero, M., Miller, P. C. \& Wateke, J. L. (eds.), Reading in Language Studies: Language across Disciplinary Boundaries 1, pp. 613-626.

Steele, K. E. (1998). The Positive and Negative Effects of the Use of Humour in the Classroom Setting. Salem, WV: Salem-Teikyo University, Education Department, Salem, WV MA thesis (unpublished).

Tuncay, H. (2007). 'Welcome to HELL: Humour in English language learning'. Education Resources Information Centre Online submission (ED499225), pp. 1-11.

Walker, R. J. (2008). 'Twelve characteristics of an effective teacher: A longitudinal, qualitative, quasi-research study of in-service and pre-service teachers' opinions'. Educational Horizons 87 (1), pp. 61-68. 